\title{
High dietary salt does not significantly affect plasma 25-hydroxyvitamin D concentrations of Sprague Dawley rats
}

\author{
Myrtle Thierry-Palmer ${ }^{1 *}$, Teclemicael K Tewolde', Neremiah L Emmett ${ }^{2}$, Mohamed A Bayorh ${ }^{3}$
}

\begin{abstract}
Background: The Dahl salt-sensitive rat, but not the Dahl salt-resistant rat, develops hypertension and hypovitaminosis $\mathrm{D}$ when fed a high salt diet. Since the salt-sensitive rat and salt-resistant rat were bred from the Sprague Dawley rat, the aim of this research was to test the hypothesis that salt-resistant and Sprague Dawley rats would be similar in their vitamin D endocrine system response to high salt intake.

Findings: Sprague Dawley, salt-sensitive, and salt-resistant rats were fed high (80 g/kg, 8\%) or low (3 g/kg, 3\%) salt diets for three weeks. The blood pressure of Sprague Dawley rats increased from baseline to week 3 during both high and low salt intake and the mean blood pressure at week 3 of high salt intake was higher than that at week 3 of low salt intake $(P<0.05)$. Mean plasma 25 -hydroxyvitamin $D$ concentrations (marker of vitamin $D$ status) of Sprague Dawley, salt-sensitive, and salt-resistant rats were similar at week 3 of low salt intake. Mean plasma 25-hydroxyvitamin D concentrations of Sprague Dawley and salt-resistant rats were unaffected by high salt intake, whereas the mean plasma 25-hydroxyvitamin D concentration of salt-sensitive rats at week 3 of high salt intake was only $20 \%$ of that at week 3 of low salt intake.

Conclusions: These data indicate that the effect of high salt intake on the vitamin D endocrine system of Sprague Dawley rats at week 3 was similar to that of salt-resistant rats. The salt-sensitive rat, thus, appears to be a more appropriate model than the Sprague Dawley rat for assessing possible effects of salt-sensitivity on vitamin D status of humans.
\end{abstract}

\section{Background}

The Dahl salt-sensitive (S) rat is a widely studied model of salt-induced hypertension [1,2]. The Dahl S rat, but not the Dahl salt-resistant rat (R), develops hypertension, accompanied by hypovitaminosis $\mathrm{D}$, when fed a high salt diet [3-5]. Plasma concentration of 25-hydroxyvitamin D (25-OHD), the liver metabolite of vitamin $\mathrm{D}$, is a marker of vitamin D status. Plasma 25-OHD concentrations are similar in young $\mathrm{S}$ and $\mathrm{R}$ rats when the rats are fed a low salt diet ( $0.3 \%$ sodium chloride). High salt intake, however, causes significant decreases in plasma 25-OHD concentrations of $S$ rats, but not $R$ rats [3,5-7]. Blood pressure was shown to be directly correlated and plasma 25-OHD concentration inversely correlated with the number of days that young $\mathrm{S}$ rats were fed an $8 \%$ salt diet

\footnotetext{
* Correspondence: mthierry-palmer@msm.edu

'Department of Microbiology, Biochemistry, and Immunology, Morehouse School of Medicine, 720 Westview Dr. S.W., Atlanta, Georgia 30310-1495, USA Full list of author information is available at the end of the article
}

$[3,6]$. We demonstrated that Dahl S rats lose proteinbound vitamin D metabolites into urine and that this loss is markedly accelerated during high salt intake [8]. High salt intake, thus, creates a vitamin D deficiency state in Dahl S rats in the presence of standard amounts of dietary vitamin $\mathrm{D}[3,5-7]$.

Since $S$ and $R$ rats were originally bred from the Sprague Dawley rat (SD) [1], we tested the hypothesis that $\mathrm{R}$ and SD rats would be similar in their vitamin D endocrine system response to high salt intake and not develop hypovitaminosis $\mathrm{D}$, as does the $\mathrm{S}$ rat.

\section{Methods}

\section{Animals and diets}

Male SD rats, Dahl S (SS/Jr) and R (SR/Jr) rats (130-150 g, 4-5 weeks old, twelve rats per type) were obtained from Harlan Sprague Dawley, Indianapolis, IN. All protocols involving animals were previously approved by the Morehouse School of Medicine Animal Care Committee.

\section{Biomed Central}


Guidelines followed were those of the Public Health Service and the revised animal welfare act as regulated by USDA. The rats were maintained as previously described [9]. They were housed in a room with $12 \mathrm{~h}$ light - dark cycles and, after one week of acclimation, six rats of each type were fed either a low $(3 \mathrm{~g} / \mathrm{kg})$ or high $(80 \mathrm{~g} / \mathrm{kg})$ salt diet (Harlan Teklad, Madison, WI) for three weeks. Diets, blood collection, and blood pressure measurements have been previously described [9].

\section{Plasma 25-hydroxyvitamin D concentration}

Plasma 25-OHD concentration was measured as previously described [3]. Plasma samples were purified using a dichloromethane/methanol liquid-liquid extraction, followed by solid-phase extraction. Fraction 1 from the solid phase extraction was used to assay for 25$\mathrm{OHD}$ by radioimmunoassay kits available at the time of the study from Amersham Corp. (Arlington Heights, IL).

\section{Statistics}

A mean \pm SEM was calculated for each group. Statistical significance $(P<0.05)$ was evaluated by the Mann Whitney test (SigmaStat, SPSS, Inc., Chicago, IL.).

\section{Results}

Blood pressure significantly increased from baseline to week 3 among all groups (Figure 1). S and SD rats, but not $\mathrm{R}$ rats, exhibited significantly higher mean blood

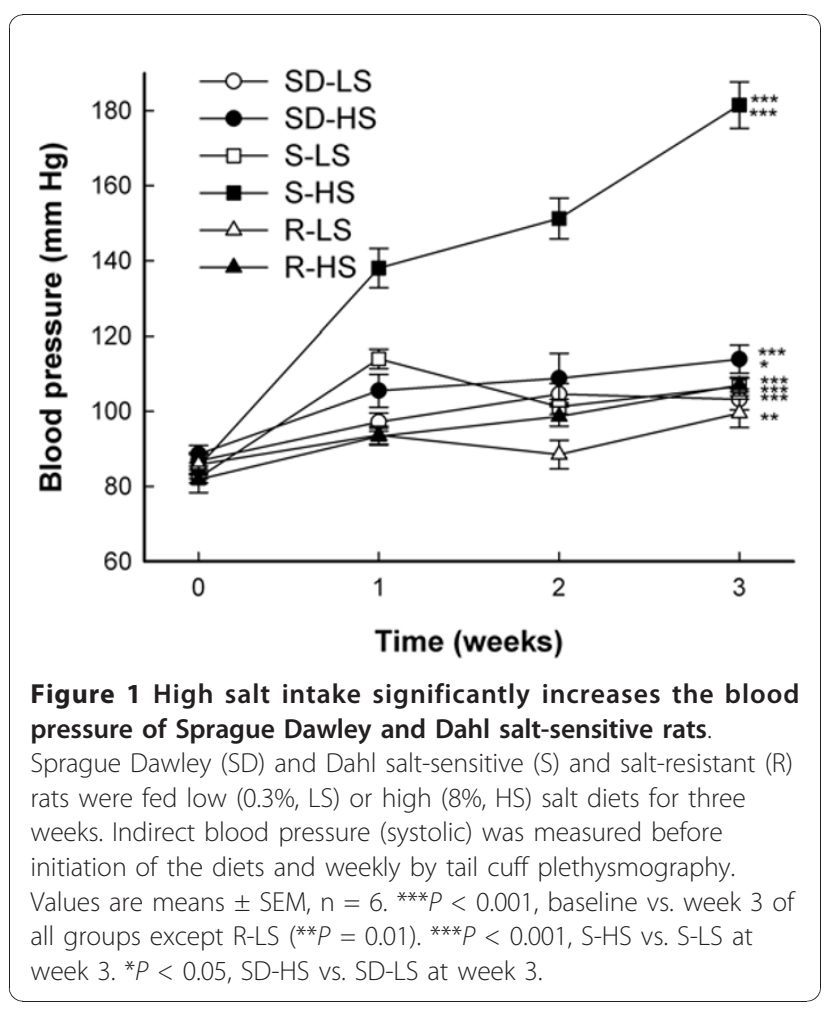

pressures at week 3 of high salt intake than at week 3 of low salt intake. The blood pressures plotted (Figure 1) are means for six rats/dietary group (set 1) of $12 \mathrm{~S}$ and $12 \mathrm{R}$ rats/dietary group in a previous report [9]. Set 1 of that study included $12 \mathrm{SD}$ rats, 6/dietary group. Mean plasma 25-OHD concentrations of SD, R, and S rats were similar at week 3 of low salt intake (Figure 2). Mean plasma 25-OHD concentrations of SD and $\mathrm{R}$ rats were similar at week 3 of high and low salt intake, whereas mean plasma 25-OHD concentration of $\mathrm{S}$ rats at week 3 of high salt intake was only $20 \%$ of that at week 3 of low salt intake.

\section{Discussion}

The blood pressure of SD rats increased from baseline to week 3 during both high and low salt intake, and the mean blood pressure at week 3 of high salt intake was significantly higher than that at week 3 of low salt intake. Mean blood pressure of SD rats at week 3 of high salt intake was $114 \pm 4 \mathrm{~mm} \mathrm{Hg}$, compared with means of $107 \pm 2 \mathrm{~mm} \mathrm{Hg}$ for $\mathrm{R}$ rats and $182 \pm 6 \mathrm{~mm}$ $\mathrm{Hg}$ for $\mathrm{S}$ rats. Plasma 25-OHD concentrations of SD and $\mathrm{R}$ rats were unaffected by high salt intake, whereas mean plasma 25-OHD concentration of S rats at week 3 of high salt intake was decreased to $20 \%$ of that at week 3 of low salt intake. These data indicate that the vitamin

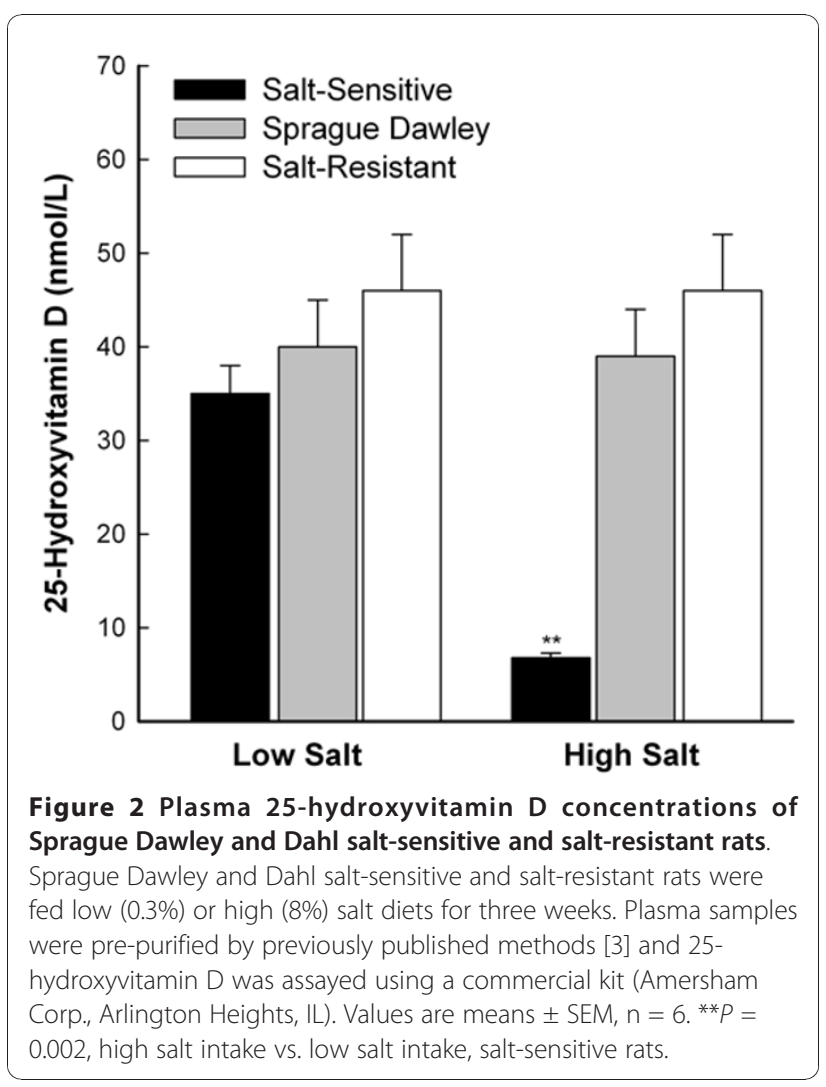


$\mathrm{D}$ endocrine system response of SD rats to a high salt load (8\%) for three weeks is more similar to that of $\mathrm{R}$ rats than to that of $S$ rats.

Dahl S rats, but not Dahl R rats, are insulin-resistant [10-12]. Ogihara et al. [13] have demonstrated that a high salt diet induces insulin resistance in both $S$ and SD rats. It has thus been suggested that the SD rat is essentially the same as the Dahl S strain [14]. Channa et al. [12] have suggested that insulin resistance and hypertension may be inherited as separate traits. In this study, the blood pressure response of SD rats to high salt intake was between that of $\mathrm{R}$ and $\mathrm{S}$ rats. This and other studies suggest that $\mathrm{SD}$ rats are similar to $\mathrm{S}$ rats in the induction of insulin resistance by high salt intake $[13,14]$, but similar to $R$ rats in the vitamin $D$ endocrine response to high salt intake. The $\mathrm{S}$ rat, thus, appears to be a more appropriate model than the SD rat for assessing possible effects of salt-sensitivity on vitamin D status of humans.

\section{Acknowledgements}

This work was supported by the National Aeronautics and Space Administration grant NCC 9-53. Facilities and support services were partially funded by the National Institutes of Health/National Center for Research Resources grants RR03034 and 1 C06 RR18386. The authors thank Min Wang for blood pressure measurements and Stacy Cephas for statistical analyses.

\section{Author details}

'Department of Microbiology, Biochemistry, and Immunology, Morehouse School of Medicine, 720 Westview Dr. S.W., Atlanta, Georgia 30310-1495, USA. ${ }^{2}$ Department of Physiology, Morehouse School of Medicine, 720 Westview Dr. S.W., Atlanta, Georgia 30310-1495, USA. ${ }^{3}$ Department of Pharmacology and Toxicology, Morehouse School of Medicine, 720 Westview Dr. S.W., Atlanta, Georgia 30310-1495, USA.

\section{Authors' contributions}

MT-P participated in the conception and design of the study and the vitamin D metabolite analysis and drafted the manuscript. TKT carried out the vitamin D metabolite analysis. NLE participated in the conception and design of the study. MAB participated in the conception, design, and coordination of the study and in the blood pressure measurements. All authors read and approved the final manuscript.

\section{Competing interests}

The authors declare that they have no competing interests.

Received: 13 August 2010 Accepted: 9 December 2010

Published: 9 December 2010

\section{References}

1. Dahl LK: Salt and hypertension. Am J Clin Nutr 1972, 25:231-244.

2. Rapp JP: Development of inbred Dahl salt-sensitive and inbred Dahl saltresistant rats. Hypertension 1987, 9(Suppl I):121-142.

3. Thierry-Palmer M, Carlyle KS, Williams MD, Tewolde T, Caines-McKenzie S, Bayorh MA, Emmett NL, Harris-Hooker SA, Sanford GL, Williams EF: Plasma 25-hydroxyvitamin $D$ concentrations are inversely associated with blood pressure of Dahl salt-sensitive rats. J Steroid Biochem Molec Biol 1998, 66:255-261.

4. Thierry-Palmer M, Cephas S, Sayavongsa P, Doherty A, Arnaud SB: Dahl saltsensitive rats develop hypovitaminosis $D$ and hyperparathyroidism when fed a standard diet. Bone 2005, 36:645-653.

5. Faqi AS, Sherman DD, Wang M, Pasquali M, Bayorh MA, Thierry-Palmer M: The calciuric response to dietary salt of Dahl salt-sensitive and saltresistant female rats. Am J Med Sci 2001, 322:333-338.
6. Thierry-Palmer M, Tewolde TK, Forté C, Wang M, Bayorh MA, Emmett NL, White J, Griffin K: Plasma 24,25-dihydroxyvitamin D concentration of Dahl salt-sensitive rats decreases during high salt intake. J Steroid Biochem Molec Biol 2002, 80:315-321.

7. Wu X, Vieth R, Milojevic S, Sonnenberg H, Melo LG: Regulation of sodium, calcium and vitamin $D$ metabolism in Dahl rats on a high-salt/low potassium diet: genetic and neural influences. Clin Exper Pharm Physiol 2000, 27:378-383.

8. Thierry-Palmer M, Doherty A, Bayorh MA, Griffin K: Dahl salt-sensitive rats excrete 25-hydroxyvitamin D into urine. J Nutr 2003, 133:187-190.

9. Thierry-Palmer M, Sherman DD, Emmett NL, Wang M, Bayorh MA, Donkok N: The calciuric response to dietary salt of Dahl salt-sensitive and salt-resistant male rats. Am J Med Sciences 2001, 321:342-347.

10. Kotchen TA, Zhang HY, Covelli M, Blehschmidt N: Insulin resistance and blood pressure in Dahl rats and in one-kidney, one-clip hypertensive rats. Am J Physiol 1991, 261:E692-E697.

11. Somova L, Channa ML: Glucose metabolism and insulin sensitivity in Dahl hypertensive rats. Methods Find Exp Clin Pharmacol 1999, 21:421-425.

12. Channa ML, Somova L, Nadar A: Facets of the metabolic syndrome in Dahl hypertensive rats. Cardiovas J S Afr 2004, 15:61-63.

13. Ogihara T, Asano T, Ando K, Sakoda H, Anai M, Shojima N, Ono H, Onishi Y, Fujishiro M, Abe M, Fukushima Y, Kikuchi M, Fujita T: High-salt diet enhances insulin signaling and induces insulin resistance in Dahl saltsensitive rats. Hypertension 2002, 40:83-89.

14. Ogihara T, Asano T, Fujita T: Contribution of salt intake to insulin resistance associated with hypertension. Life Sciences 2003, 73:509-523.

doi:10.1186/1756-0500-3-332

Cite this article as: Thierry-Palmer et al:: High dietary salt does not significantly affect plasma 25 -hydroxyvitamin $\mathrm{D}$ concentrations of Sprague Dawley rats. BMC Research Notes 2010 3:332.

\section{Submit your next manuscript to BioMed Central and take full advantage of:}

- Convenient online submission

- Thorough peer review

- No space constraints or color figure charges

- Immediate publication on acceptance

- Inclusion in PubMed, CAS, Scopus and Google Scholar

- Research which is freely available for redistribution

Submit your manuscript at www.biomedcentral.com/submit
Ciomed Central 